\title{
Peer relations and access to capital in the mathematics classroom: a Bourdieusian social network analysis
}

DOI:

10.1080/01425692.2016.1245129

\section{Document Version}

Accepted author manuscript

Link to publication record in Manchester Research Explorer

\section{Citation for published version (APA):}

Choudry, S., Williams, J., \& Black, L. (2017). Peer relations and access to capital in the mathematics classroom: a Bourdieusian social network analysis. British Journal of Sociology of Education, 38(7), 1037-1053.

https://doi.org/10.1080/01425692.2016.1245129

\section{Published in:}

British Journal of Sociology of Education

\section{Citing this paper}

Please note that where the full-text provided on Manchester Research Explorer is the Author Accepted Manuscript or Proof version this may differ from the final Published version. If citing, it is advised that you check and use the publisher's definitive version.

\section{General rights}

Copyright and moral rights for the publications made accessible in the Research Explorer are retained by the authors and/or other copyright owners and it is a condition of accessing publications that users recognise and abide by the legal requirements associated with these rights.

\section{Takedown policy}

If you believe that this document breaches copyright please refer to the University of Manchester's Takedown Procedures [http://man.ac.uk/04Y6Bo] or contact uml.scholarlycommunications@manchester.ac.uk providing relevant details, so we can investigate your claim.

\section{OPEN ACCESS}




\title{
Peer relations and access to capital in the mathematics classroom: a Bourdieusian social network analysis
}

\author{
Sophina Choudry, Julian Williams and Laura Black \\ The University of Manchester, Manchester, UK.
}

\begin{abstract}
The aim of this paper is to explore the structure of social capital in peer networks and its relation to the unequal access of educational resources within mathematics classrooms. We hypothesise that learners can gain access to mathematics through friendship networks that provide more or less help from peers that might sustain (or curtail) their mathematics learning based on a Bourdieusian framework. We report a Social Network Analysis of mutually-recognised helping within friendship groups. This is complemented by observation and interviews that illustrate how different classrooms have different network structures, positioning learners of different ethnic minorities and genders in significantly different ways regarding access to learning. We argue that friendship networks mediate social capital and access to further cultural capital, and that this may help explain structural differences in attainment. As ethnicity and gender, inter alia, mediate friendship networks, they also mediate access to capital in the classroom.
\end{abstract}

Keywords: mathematics; peer group; social capital; social network analysis; Bourdieu

This is an Author's Original Manuscript of an article published by Taylor \& Francis in British Journal of Sociology of Education [due to be published] and will be available online at http://www.tandfonline.com/doi/full/10.1080/01425692.2016.1245129

\section{Background}

The aims of this paper are twofold: (i) to explore how friendship networks (and hence ethnicity and gender) mediate social capital and, thereby, access to further cultural capital; and (ii) to make a methodological contribution which outlines how students' subjective perceptions of friendship and the mathematics help provided by their peers can be objectively captured in the form of a social network analysis within classrooms. Thus, the paper aims to shed light on the value of such networks, but also to illustrate how social network analysis can be used in a classroom to reveal differences in learning opportunities offered to different groups of students by their peers.

Over the past few decades, researchers in the field of psychology and sociology have demonstrated how inter-personal relations within peer groups can impact educational attainment outcomes, as well as aspirations for further study (see Wallace 1966; Rossem et al. 2013). Classroom based research at secondary level (aged 11-16), both in the US and the UK, has looked at peer group effects on attainment in terms of friendship groups formed within classrooms (see Hallinan 1983). For instance, Epstein (1983) found in his study that both highand low-attaining students with high-attaining friends were able to gain higher grades at the end of a school year compared to their peers with lower attaining friends.

Studies of peer group effects on attainment, motivation and educational aspirations have distinguished between peer relations that are (i) within close friendship dyads (Berndt \& Keefe 1996); (ii) friendship (peer) groups (Wentzel and Caldwell 1997); and (iii) peer networks (Kindermann 1993). Cairnes, Xie and Leung (1998) argue that peer effects on education need to be explored through social networks from an individual as well as a group/network perspective: 'a broader view would include the pool of relationships from which friendships emerge and into which they submerge: namely, the social network in which children are embedded and the specific groups of which they are members' (p. 29), whereas close friendship dyads only 
represent 'part of the picture of peer relationships' (p. 29). Other studies have taken up this stance and evaluated peer networks using Cairns, Perrin and Cairns (1985) social map approach, in which students get asked 'who hangs around with whom' during interviews in order to map out the peer networks (see Kindermann 1993). Though such an approach is useful in evaluating subjective perceptions of peer networks (i.e. students are asked who they are friends with and a map is formed on this basis), we will argue, following Bourdieu, that these subjective perceptions need to be evaluated in terms of the objective (i.e. mutually or socially recognized) positions held by students within the educational field. (N.B. we use the terms 'field', 'capital', etc. in the way Bourdieu has appropriated them). We argue that an appropriate social network analysis can define the objective relations within the educational field. We argue the need to establish how peer networks can mediate access to mathematical knowledge, and how they can be mediated by relations of gender and ethnicity. However, we also acknowledge that there may be other values in friendship networks that are not explored here and are not within the scope of this paper.

In exploring gender roles in such networks, Boaler (1997) has argued that girls, grouped or paired together with friends for an open ended mathematical task, are more likely to converse in relation to the set task and enhance their learning experience in comparison to boys. Kutnick, Blatchford and Baines (2005) have confirmed that friendship-based pairings within classrooms can enhance cognitive learning processes, where girl-girl friendship pairings (with similar prior attainment levels) consistently outperform their male counterparts, at all ability level pairings, in every year group. This contrasts with male-male acquaintances (rather than friends) who perform better than male-male friends at the same tasks. Kutnick, Blatchford and Baines (2005) attribute these variations in their findings to the orientation of social capital as accounted for in students' friendship groups which may be either focused inwards towards the school culture (as generally in the case of more compliant girls - aligned with the expectations of the school) or outwards (i.e. aligned against the expectations of the school, as generally in the case of less compliant boys). Nevertheless, they acknowledge that further research is needed to investigate such 'orientations' in terms of social capital. All this is suggestive of the importance of social capital in social networks, which is the focus of this paper.

Yet in the wider social theory literature, there is a debate on what social capital is. Heath, Fuller and Johnston (2010) demonstrate how perceptions and experience of Higher Education (HE) by young people can facilitate the transmission of capital within young peoples' 'social networks of social capital' (p. 395). Such social capital acts as a form of bridging capital to nonHE experienced family members and therefore shapes their perceptions of a future where continuing on to HE becomes possible. For us the key difference between Coleman/'s notion of social capital (drawn on by Heath et al.) and Bourdieu's concept is simply that Bourdieu is a critic of 'capital' while Coleman/Putnam treat it as if it is the requirement for and nutrient of an agentic life.

Whilst the role of social capital in shaping young people's learning trajectories has been widely adopted by policy-practice audiences using Coleman's approach (1988), much of this work focuses on subjective accounts of the students, and most theoretical models arguably lack rigour in their 'conceptualization and measurement' and do not 'acknowledge differential access to social networks and social resources' (Dika and Singh 2002, 46). However, at the same time, 'there is very limited research on the differential effects... of either organisational or within-class groupings' (Kutnick et al. 2005, 4) and further research is needed, specifically adopting a Bourdieusian framework, which objectivises the subjective, i.e. effectively measuring and unpacking the complexity of how social capital is constituted and can be operationalised in peer networks. We aim here to fill the gap in the literature through a particular social network analysis, revealing how social capital might impact on learning processes, and hence educational outcomes (cultural capital) to varying degrees. We do this by objectifying peer group structures as representations of individual students' access to mathematics learning opportunities, and as mediated by attainment, ethnicity and gender. 


\section{Theoretical framework}

In the study of the French Education System, Bourdieu and Passeron (1977) found that the possession of social and cultural capital (and also linguistic capital) was directly related to the degree of success of students, and how they were differentially selected and positioned in schools, courses and ability groups. The selection process then either limited or enhanced their access to further cultural capital available in the educational field. Here social capital is:

...the aggregate of the actual or potential resources which are linked to possession of a durable network of more or less institutionalized relationships of mutual acquaintance and recognition or in other words, to membership in a group which provides each of its members with the backing of the collectivity-owned ... capital, a "credential" which entitles them to credit, in the various senses of the word. These relationships may exist only in the practical state, in material and/or symbolic exchanges which help to maintain them. (Bourdieu 1983,249)

From a Bourdieusian perspective the mathematics classroom is a social space where dynamic relations between peers and teachers are in a constant flux, and this provides a site of struggle over, inter alia, cultural capital valued in the wider educational field. Such cultural capital is constituted in part as mathematical knowledge and dispositions, but access to this form of capital in classroom practice may be mediated by classroom interactional practices, including relations between student and teacher, and between students and students, i.e. the peer relation. Clearly these relations are also mediated by gender, ethnicity and class, and so may explain how schooling reproduces social relations of power. In this analysis we define mathematicaleducational cultural capital as embodied in a combination of mathematics qualifications, skills, understandings, dispositions, etc. However, a key part of the relational process involved in the emergence of this cultural capital may be the associated social capital that arises by virtue of access to capital through one's social networks in the social space of the classroom, or outside in the family, etc. This social capital may allow for opportunities to grow one's cultural capital, and is constitutive of capital itself in this sense, i.e. a potentiality to grow cultural capital. In general, we hypothesise a relation between social, cultural and the accumulation of educational, capital: i.e. that in school, the interaction of social capital with cultural capital can lead to accumulation of further educational capital (social capital X cultural capital $=>$ accumulation of educational cultural capital). Therefore we focus in this paper on how social ties play a role in unequal access to educational opportunities and in particular in access to mathematics-educational, cultural capital in the classroom. Using Bourdieu, we evaluate friendships amongst peers in the form of networks within the mathematics classroom as potentially providing this social capital. Bourdieu notes that the:

...volume of the social capital possessed by a given agent depends on the size of the network of connections... effectively mobilize[d] and on the volume of the capital (economic, cultural or symbolic) possessed... by each of those to whom... [one] is connected. (Bourdieu 1983, 249)

In other words, in any given network (or sub-network) found within a classroom its total amount of social capital is dependent on the average of capital available to this network and its size. And for an individual, the connection to a network with a high volume of capital may potentially enable them to access further cultural capital (for example, educational cultural capital).

We conclude that there is a gap in the literature here and will argue that social network analysis, appropriately devised, might help fill this gap. Thus we ask the research question:

What is the objective structure of peer network relations and how does this mediate learning opportunities in mathematics classrooms? 


\section{Methodology}

\section{Data sample}

We present findings by providing a comparative case study analysis of the social networks operating in two specific mathematics classrooms. The two schools in which our 'case' classrooms are situated were selected on the basis of our statistical analysis, that is multilevel analysis of data obtained from the National Pupil Database to examine interaction of background variables (ethnicity, class and gender) on GCSE Mathematics grades. Thus, our analysis here is framed by a larger study we have undertaken, which maps out social reproduction in mathematics education for different groups of students with a specific focus on Pakistani students' attainment and engagement with mathematics learning opportunities (Choudry, 2016). Both schools discussed in this paper were identified as high attaining generally, that is schools with above average proportion of students predicted to get a grade $A^{*}-\mathrm{C}$ in GCSE mathematics. However, they contrast in terms of their contextual value added to Pakistani students' attainment. One school performed as predicted given the school's ethnic and social class demographics (i.e. the main effect) by adding least value to Pakistani students' progress (compared to White British students). The second school challenged the main effect by performing better than would be predicted (i.e. as an extreme positive outlier). Here, better than would be predicted refers to schools that are adding value to the Pakistani ethnic group in terms of progress with mathematics attainment. In other words, these are schools in which Pakistani students are predicted to have greater likelihood of obtaining grade C plus in their GCSE mathematics exams than would typically be expected, after controlling for all other background factors.

Our analysis below focuses on the (Year 8) mathematics classroom selected from the outlier school in the first instance. We call this classroom the 'advantaged' case. The second classroom (Year 10) is called the 'predicted' case. In the advantaged case (Year 8), there are a total of 26 students out of which 4 have identified themselves belonging to the Pakistani ethnic category (according to the school data). Similarly in the predicted case (Year 10) there are a total of 27 students out of which 5 have identified themselves as from the Pakistani ethnic category (according to the school data).

Both classes have been identified as high attaining sets (as described by their class teachers). Thus both classes comprise a majority of students predicted to achieve grades $\mathrm{A}$ to $\mathrm{C}$ in their end of compulsory school GCSE mathematics exams. In the advantaged case, 18 students (out of 24) were on target to obtain Grade C and higher in their GCSE mathematics exams. Similarly 22 students (out of 27) were also on target in terms of their predicted performance in their mathematics exams.

\section{Method}

Case study data collected in each classroom included: classroom observations of 12 mathematics lessons, 2 teacher interviews, student questionnaires, interviews with approximately 5 students (depending on the number of Pakistani students present within the classrooms) and the collection of attainment data on each pupil.

We have used this data to give initial insights into the groupings and social relations in each class but the social network analysis, which forms the key contribution of this paper, draws on student questionnaires regarding their friendships and the giving and receiving of mathematics help in their classrooms (see below).

The questionnaire was distributed to all students and the responses were analysed to construct a network structure for each 'case' classroom (see Scott 2000). This was done using responses (i.e. rating scale from 0 to 3 with 3 being the highest) to four questions: 
1. Q1 - Who do you go to for help with your mathematics work?

2. Q2 - Who comes to you for help with their mathematics work?

3. Q3 - Who do you hang out within mathematics lessons?

4. Q4 - Who do you hang out with outside of lessons?

These responses were used to identify any sub-networks that are formed according to two constructs: (i) mathematics help given to (Q1) and received from peers (Q2); (ii) friendships inside (Q3) and outside of classroom (Q4); and we also explored the correlation between these two (i.e. Q1Q2 with Q3Q4). Here, we argue that such in depth analysis (i.e. mapping the relations between all students within the classroom in this way) is absolutely necessary in order to explore the role of social capital in peer networks in relation to mathematics learning. Where necessary, we have also backed our findings with other case study data (i.e. our observational insights and interview data with the students and teachers).

To construct each social network we used the software UCINET 6 and then visualised each network using NetDraw. Thus, the classroom network was explored through the following inbuilt functions of the UCINET software:

1) A Centrality Measure: this gives us an insight into each student's connection with other students for each of the questions asked without taking any sub-networks into account (see Newman-Girvan method below). It allows us to identify mainly (i) who are the most influential students in the class (highest in-degree or number of incoming ties) and who are the most prominent (highest out-degree or number of outgoing ties). For example, if a lot of students choose student A whom they go to help to for mathematics (Q1), student $A$ has the highest incoming ties and is considered influential. Similarly, if another student B has a high degree of outgoing ties (for Q1), it means that he or she is seeking help in mathematics from many sources and is prominent in the class for seeking help. Both influence and prominence here are measures of who is central in the classroom.

2) Mutually recognised relations through multiplex analysis: before running the analysis for identifying any sub-networks within the class network (through Newman Girvan method see below), it was important to identify only ties that were representative of a perceived mutual alliance. Therefore, multiplex analysis was performed (again) using UCINET. Mutually recognised ties were established as:

a) Social capital in relation to mathematics help given/received - to begin with, matrices for questions 1 and 2 were dichotomised ( $0=$ no response and $1=1$ and higher), and the question 2 matrix was then transposed, for matrix multiplication. The resultant multiplex matrix then shows who is connected to each other in terms of the following relations: $0=$ no ties; $1=$ only Q1; 2 = only Q2; $3=$ both ties Q1 and Q2. In other words who you go to help for mathematics (Q1) is confirmed by the other person's perception that you approach them for help in mathematics (Q2) (this forms output 3 in the resultant Q1Q2 multiplex matrix).

b) Mathematics social capital in relation to the friendship structure of a classroom. The Q1Q2 multiplex matrix (from step 2a above) is combined with the Q3Q4 multiplex matrix through another multiplex analysis in order to analyse whether mathematics help received or given is related to friendships between students of a particular class.

3) The Newman Girvan method: This iterative algorithm was applied to the matrices obtained from the previous multiplex analyses (i.e. including only the mutually recognised ties identified above and ignoring the rest). This enabled us to identify any sub-networks by selecting the relevant functions within UCINET. The software then produces a set of values 
for each tie, which can then be visualised using the in-built NetDraw function (see Hanneman \& Riddle 2005).

4) E-I index: Once sub-networks are identified, we check for homophily between them by applying the E-I index (see DeJordy \& Halgin 2008). An E-I index of -1 indicates that the network is totally focused on itself (homophily) and an index close to +1 would indicate that the network is totally focused outwardly (heterophily) (Krackhardt and Stern, 1988). In other words, within a classroom we would be able to ascertain, if members of sub-networks (that are found) interact, i.e. have ties, with each other (for example) in terms of mathematics help, or lean towards network closure.

Where applicable attribute or descriptive data such as ethnicity, gender and prior attainment in mathematics (as a proxy for individual mathematics cultural capital) has also been taken into account and used to evaluate a group's social capital.

\section{Findings}

The findings, outlined below, are structured around mainly the advantaged case (case 1) to illustrate the main effects of peer networks on educational learning opportunities in mathematics. We have included findings from the predicted case (case 2) in order to illustrate that peer networks based on friendships can have varying impact on students' educational cultural capital compared to case 1 .

Our account of each case begins with observational insights by one of us who also took on the role of teaching assistant during the data collection period. We then present the social network analysis and discuss how this enables quantitative analysis of peer networks in terms of access to peer learning opportunities.

\section{Advantaged Case (1)}

\section{Observational insights}

In this school (especially in mathematics), classrooms are organised according to prior attainment levels of students with similar abilities seated together. Students are not allowed to sit wherever they want to during a regular lesson. However after a mathematics test in one of the observed lesson, students were allowed to choose wherever they wanted to sit in order to prepare for an upcoming science exam. What took place next was a shuffling and shifting of the room including joining up of some of the tables. During the first shuffle, most students decided to sit next to their friends and a few stayed where they were. Some of the (higher attaining) Pakistani boys took the initiative to join the middle tables together and sit around them. These boys were then joined by others (average attaining boys) who were almost immediately asked to leave by the already seated boys. Evidently, these boys were the only ones who needed to re-adjust tables and when prompted for the reasons for doing so, Umar (a higher-attainer; Pakistani boy) indicated that David (lower-attainer; White British) and Hardeep (lower-attainers from the 'other' ethnic group) were disturbing them and were not considered welcome to join their table as 'friends', and would also disturb them 'in their studies'. Interestingly, most students had rearranged themselves according to gender, i.e. all females were sitting in pairs, there were a few male pairs, but then the aforementioned larger male group. Analysis of this temporary seating arrangement according to the students' background data (such as prior attainment, gender, ethnicity, etc.), revealed that the larger male, 'studious' table consisted of higher-attainers and also were mainly Pakistani boys. Hence the class re-organised itself according to attainment, but also by: 
- gender: majority of the students appeared to have segregated themselves according to their gender; and

- ethnicity: male, apparently 'studious' (as per teacher's view and their own explanation for rejecting others).

Another relevant event took place when one of us acting as the informal teaching assistant was asked by the classroom teacher to provide one to one tutoring/teaching to a few high mathematics attainers in this class. Her role was to teach a selected subgroup some higher-level mathematics content (so-called level 6, such as finding a solution to algebraic equations through trial and improvement) during their usual lesson time. These students were: Shabana, Aftab, Umar, Lewis and Susan. Interestingly, Susan was included in this group as she had achieved a level 5a (the highest benchmark before level 6) in her last mathematics test. Mr. Wilkes (the class teacher) explained that this 5a was a good result given that she was seen as highly disruptive, and that maybe in a quieter and smaller group she could possibly achieve more. However, Susan did not respond positively to being apart from her friends, and she continuously protested that she wanted to go back to the classroom to friends and refused to do any of the set tasks. During group interviews, students were asked about the teacher's practice of exposing only specific selected students to higher-level mathematics. Umar (one of the higher attaining Pakistani boys in the class) replied that this practice was 'fair' (Umar, student interview), but the girls understood it to be unfair and insisted that these students should be moved to higher sets rather than gaining special attention in 'their' classroom. The females (in a group interview) were also quite accepting of the idea of not having access to higher-level mathematics, whereas for the high attainers further mathematical knowledge was considered as their right.

In summary, in the first, advantaged case, a minority group of studious students, mainly Pakistani boys - some of whom were higher attainers - was identified. Much of the rest of the class appeared to be dominated by a group led by several apparently disruptive girls, who were mostly, but not exclusively, more average in attainment, and who were aware of this distinction. The next section will demonstrate the findings from SNA of this class in order to objectively measure the relationships involved, and so help to understand how the classroom space is structured into social networks.

\section{SNA - Advantaged Case}

As an initial analysis we checked for centrality measures within this case for Q1 to Q4. We identified (for example for Q1) Shabana (Pakistani female high attainer) as having the highest number of in-degree ties (13) i.e. she was the most influential in terms of providing help in mathematics. In other words, 13 students indicated that they go to Shabana for help in mathematics. On the other hand, Susan has the highest number of out-degree ties for Q1 and Q2, indicating that she is the one seeking help in mathematics from many sources (Q1); and that she perceives herself as highly influential in terms of her fellow peers accessing her for mathematics work (Q2). Susan is also found to be central in terms of friendships inside of the classrooms (Q3) with 23 students indicating that they are friends with Susan (prominence) and Susan choosing 30 students who she thinks she hangs out with as friends (influence).

Sub-networks within the 'advantaged' mathematics classroom. Figure 1 shows ties that are mutually recognised. For example, an arrow from Aftab directed towards Arif indicates that (i) Aftab says he goes to Arif for help in mathematics and (ii) Arif has confirmed this relation too. A double-sided arrow indicates that both students say they help each other in mathematics and both have confirmed this relation independently in the questionnaire. Two sub-networks have been found through the analysis, which we refer to sub-network A and B for now. 
After adding gender, ethnicity and prior attainment data to the Q1Q2 analysis, we have found that all high mathematics attainers in this class (such as Shabana, Umar, Aftab and Lewis - larger node labels in Figure 1) are members of sub-network A exclusively.

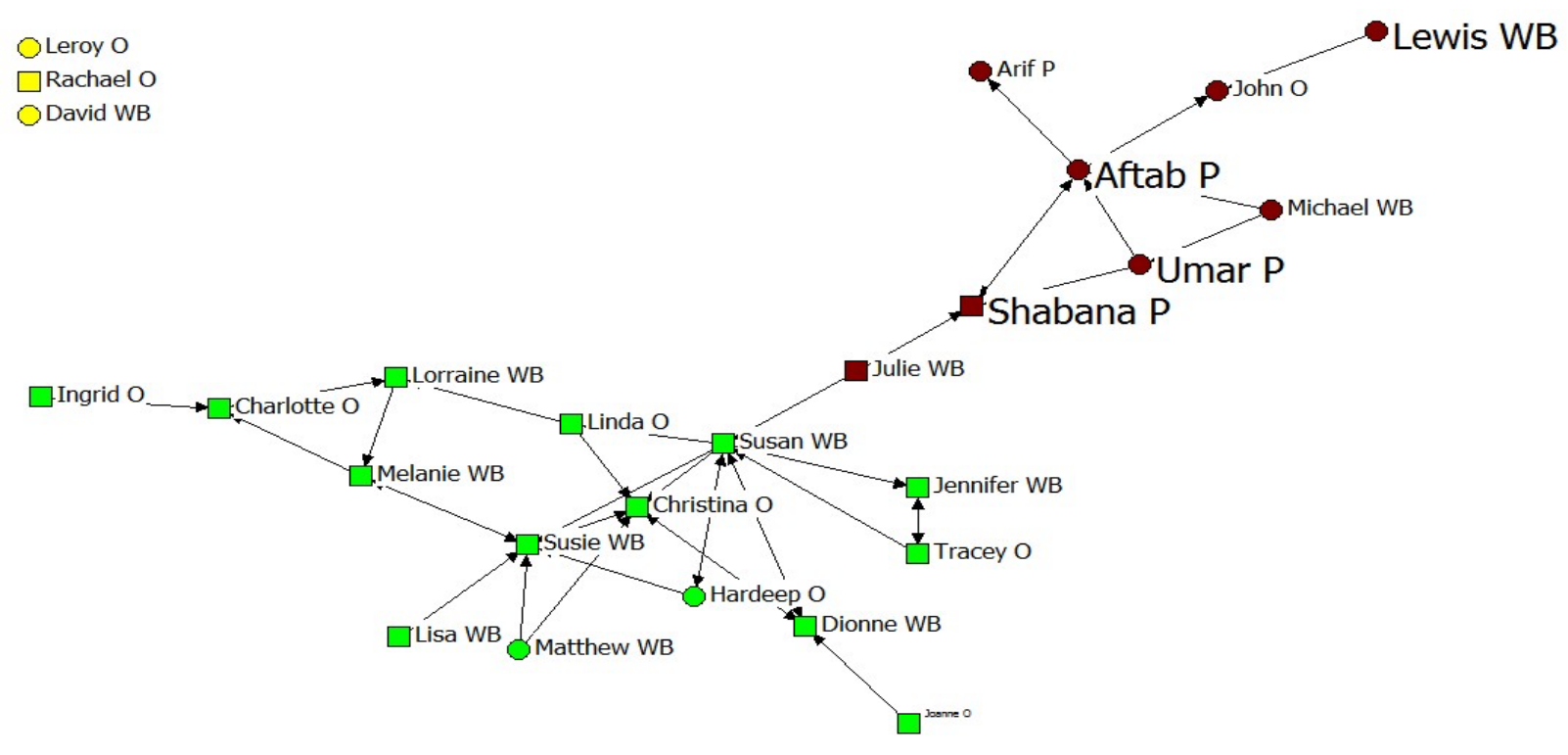

Figure 1 - Q1Q2 SNA with gender $($ female $=$ squares, male $=$ circles $)$, ethnicity $(P=$ Pakistani, $W B$ $=$ White British, $\mathrm{O}=$ Other) and attainment in Year 8 mathematics test (larger font $=$ higher level) - advantaged case

Sub-network A mainly consists of higher attaining Pakistani boys, thus supporting the observational findings. Sub-network B consists of average and one lower-attaining student. This implies that mathematics help given or received is directly related to the students' level of attainment in this particular case. We will from here on refer to a network with high attaining students as possessing high mathematics social capital and vice versa and individuals receiving help from such a network as having access to (further) higher mathematics capital. Thus from here on we will refer to sub-network A as the studious network offering higher capital and subnetwork B as the other or non-studious network.

The next stage of the analysis involves looking at how mathematics help given or received relates to friendships inside and outside of the classrooms. To what extent is the help mediated by friendship in the peer group, and what is the role of gender, ethnicity, and attainment?

Impact of friendships on students' mathematics social capital. In Figure 2, the non-studious network (the largest sub-network) has been further sub-divided into what we are calling now a purely female sub-network with Susie and Melanie being mutual friends from different subnetworks. 


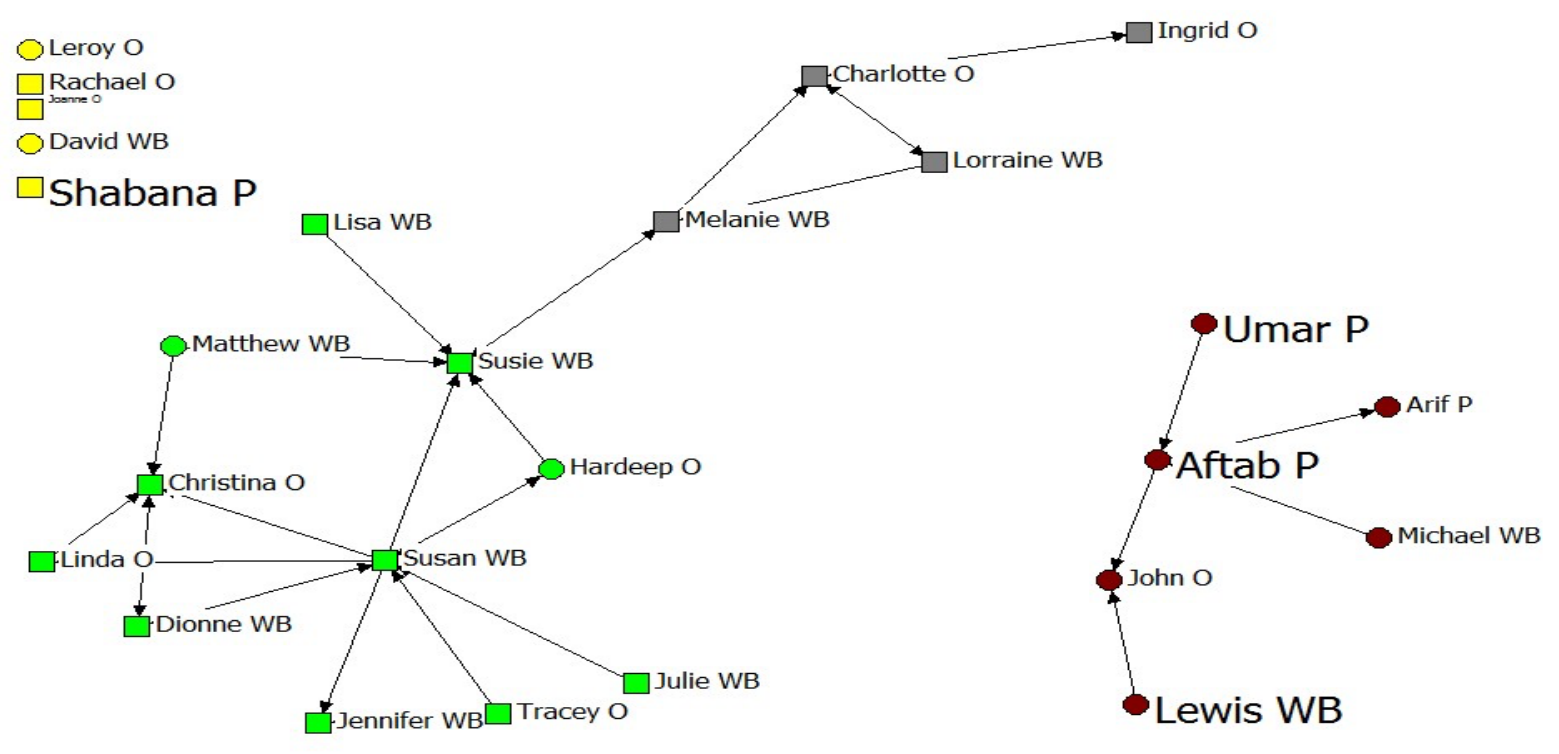

Figure 2 - Mathematics help/given received by friends - advantaged case

As in Figure 1, the studious friendship sub-network consists of mainly high attaining Pakistani boys, though not exclusively. Similarly, the non-studious sub-network is predominantly female with the exception of Matthew and Hardeep. Shabana appears isolated. Hence, there appears to be a gender-divide in this particular classroom, which extends beyond mathematics help given/received. It also appears to be based on friendships again similar to the observation of the emergent clusters in class. We next checked whether the sub-networks interact with each other:

Table I - Sub-network level E-I index for prior attainment in mathematics - advantaged case

\section{Group Level E-I Index}

\begin{tabular}{c|c|c|c|c}
\hline Sub-Networks & Internal & External & $\begin{array}{c}\text { Tota } \\
1\end{array}$ & E-I \\
\hline Studious & 10 & 0 & 10 & -1.000 \\
Non-studious & 30 & 1 & 31 & -0.935 \\
Female & 8 & 1 & 9 & -0.778 \\
Isolates & 0 & 0 & 0 & 0.000
\end{tabular}

In Table 1, it is evident that all three sub-networks found in this particular classroom are tending towards group closure, i.e. helpful friendship is apparent within the sub-network and there is little helpful friendship interaction between the sub-networks. Specifically the studious network has no interaction with the others.

In summary, it has been shown that in this classroom there are 2 sub-networks of students, each of which mainly report receiving and providing mathematics help to and from its own members (in varying degrees) with only rare help across sub-networks. One network consists of the bulk of the class, and is generally of average attainment (level 5), and less social capital, which we have called the non-studious sub-network. The smaller, studious sub-network includes all of the Pakistani boys and all of the higher attaining pupils in the class, and we argue it has higher social capital relevant to mathematics education. In fact, when mutually recognised friendships are taken into account in relation to mathematics social capital, there appears to be a further gender division with a third sub-network emerging from the others as an all-female sub- 
network with other formations staying the same. The conclusion then about this class is that the mutually-helping sub-networks correlate with (but are not identical to) peer friendships in and outside of the classroom. These friendships are also mediated by gender and ethnicity. This then may explain why, for example, Susan was resistant to the idea of having access to a higher level of mathematics outside of her usual learning environment and away from her friends. Susan has been identified in the analysis as a highly influential and prominent person in this friendships sub-network. She has also been identified as belonging to the average attaining, mostly female sub-network. She rejects the idea of learning mathematics outside of her friendship sub-network. In general, she appears to be primarily concerned about these friendships even within the classroom.

On the other hand, members of the studious network appear to have similar educational expectations to their mathematics class teacher (as was apparent in the case study - the findings of which are not fully reported in this paper) and appear to give primacy to mathematics learning over friendships within that network. They recognise themselves as studious, and are prepared to mutually help Shabana even though she is not categorised as a friend. Thus, we argue, peer groupings into these sub-networks may be an emergent phenomenon in which social and cultural capital serve to reinforce one another, and both are mediated by structural relations including ethnicity and gender.

\section{Predicted Case (2)}

\section{Observational Insights}

Our second case is regarded as similar in attainment (i.e. in terms of prior attainment outcomes and predicted GCSE mathematics grades of the students) to the advantaged case. But practices in this school are different in some respects and Pakistani students in this school perform as predicted in our statistical work. If there were a connection between these two, we might have expected to find differences in classroom structures, though they may not be associated with peer groupings, of course. We report this case here mainly because it does reveal a different structure to the advantaged case, and particularly in how Pakistani learners are socially positioned.

Unlike the advantaged case, this Year 10 class does not follow a particular seating plan based on attainment levels or grades achieved in mathematics tests. During the observed lessons, students where allowed to sit 'where they wished' in order to encourage 'mathematical discussion' (Year 10 class teacher). Once seated, the students remained in their seated location until the end of term.

As before, the observer-researcher (first author) was asked to assist the students in their mathematics tasks within classroom, but with no particular group of students being singled out. In general, the mathematics teacher of this class applied a learning strategy that encouraged students to provide peer support and actively carry out pair and group tasks. As the teacher explained, this was the reason students were allowed to sit with friends, as it could potentially enhance mathematical dialogue in the classroom. The classroom desks were laid out in rows. As a result, observations of seating arrangements suggested at least three distinctive group or pair formations within the classroom. In fact a very distinctive third row of four average-attaining Pakistani boys (Saqib, Adnan, Naveed and Rizwan) and one average attaining boy from the other minority ethnic group (Akshay) appeared to be working closely together (i.e. students peer marking each other's work and providing mathematics help in tasks where needed). Similarly, the fourth row consisted of four White British students (two boys and two girls) that appeared to be only working with each other. A third group of Nasir (high attaining Pakistani boy), Shahid (average attaining Pakistani boy) and Sunil ('Other' ethnic group) were quieter compared to the other two. At times Shahid would interact with the third row of Pakistani boys. The rest of the class appeared to be cross interacting between different students with no specific pattern. For example, row 1 would frequently turn to row 2 and vice versa. 
In summary, it appears that there is an emergence of clustering: peer support in mathematics appears to be mediated by friendship associations, which is also encouraged by the specific learning strategy the teacher applies in this classroom. In the next few sections, we will demonstrate how friendship networks mediate social capital in this specific case and does not necessarily provide access to further mathematics cultural capital.

SNA - Predicted case

Sub-networks within the mathematics class (case 2). At this point, it is important to note that Figure 3 represents the sub-networks based on a category 3 response, i.e. 'almost always': a higher level criterion than in the advantaged case.

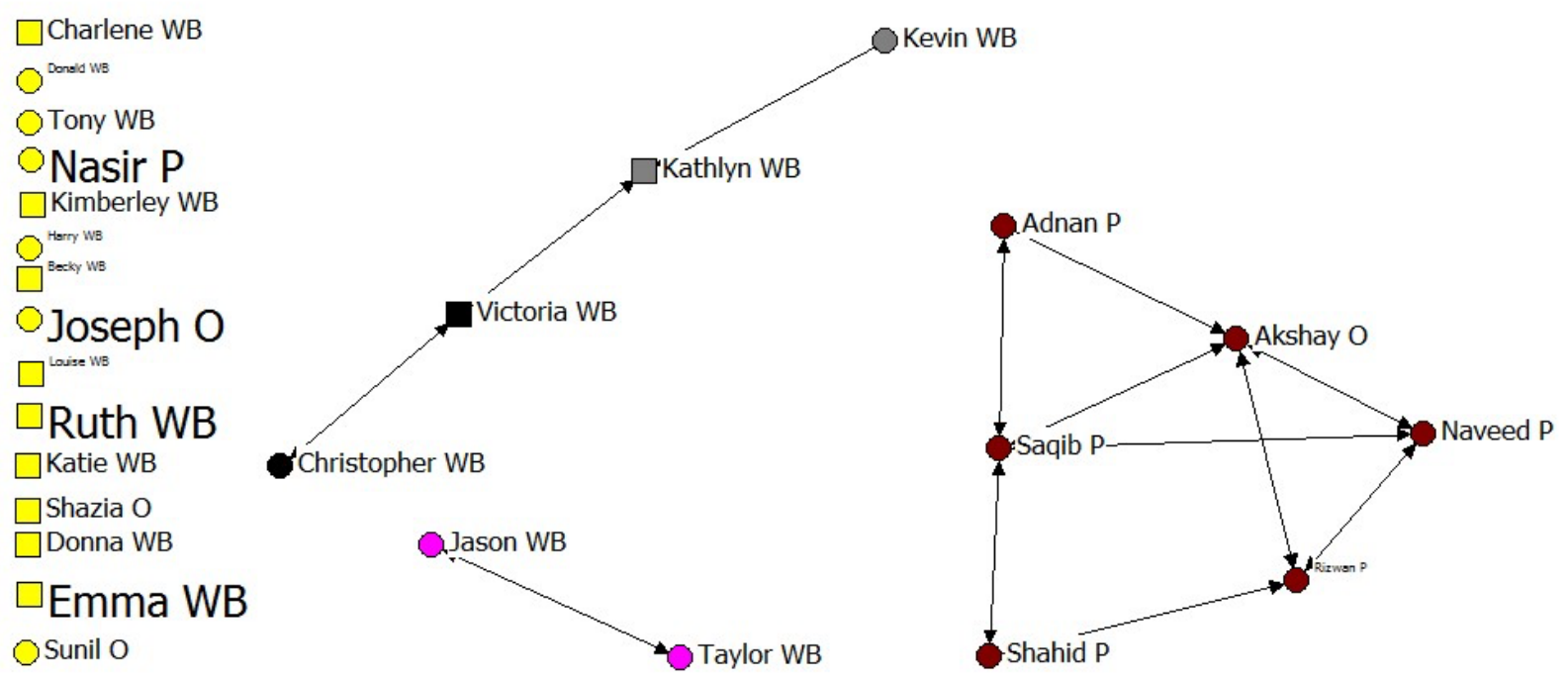

Figure 3 - Q1Q2 SNA with gender $($ female $=$ squares, male $=$ circles $)$ ethnicity $(P=$ Pakistani, $W B=$ White British, $O=$ Other) and attainment in Year 8 mathematics test (larger font $=$ higher level) predicted case

Adding ethnic grouping data (see Figure 3), it is evident that this large network consists of mostly Pakistani male students with the exception of Akshay (a male who belongs to the other ethnic minority category). This network also appears to be of lower mathematics capital based on their average prior attainment. Therefore, we call this sub-network simply boys. Interestingly, the only high attaining Pakistani student (Nasir) is not part of this sub-network. In fact, none of the high attaining students in this class are part of this sub-network. Thus, we suggest this subnetwork offers little capital of relevance to privileging access to mathematics help, i.e. little social capital in the wider educational field.

Impact of friendships on students' mathematics social capital. Comparing Figure 3 to Figure 4, it is evident the overall sub-network remains the same when strong friendships are taken into account and correlated to mathematics help given/received (with the exception of Kevin becoming an isolate). This again shows that peer sub-networks based on friendships are strongly correlated to those sub-networks from which mathematics help is given or received (Figure 3). 


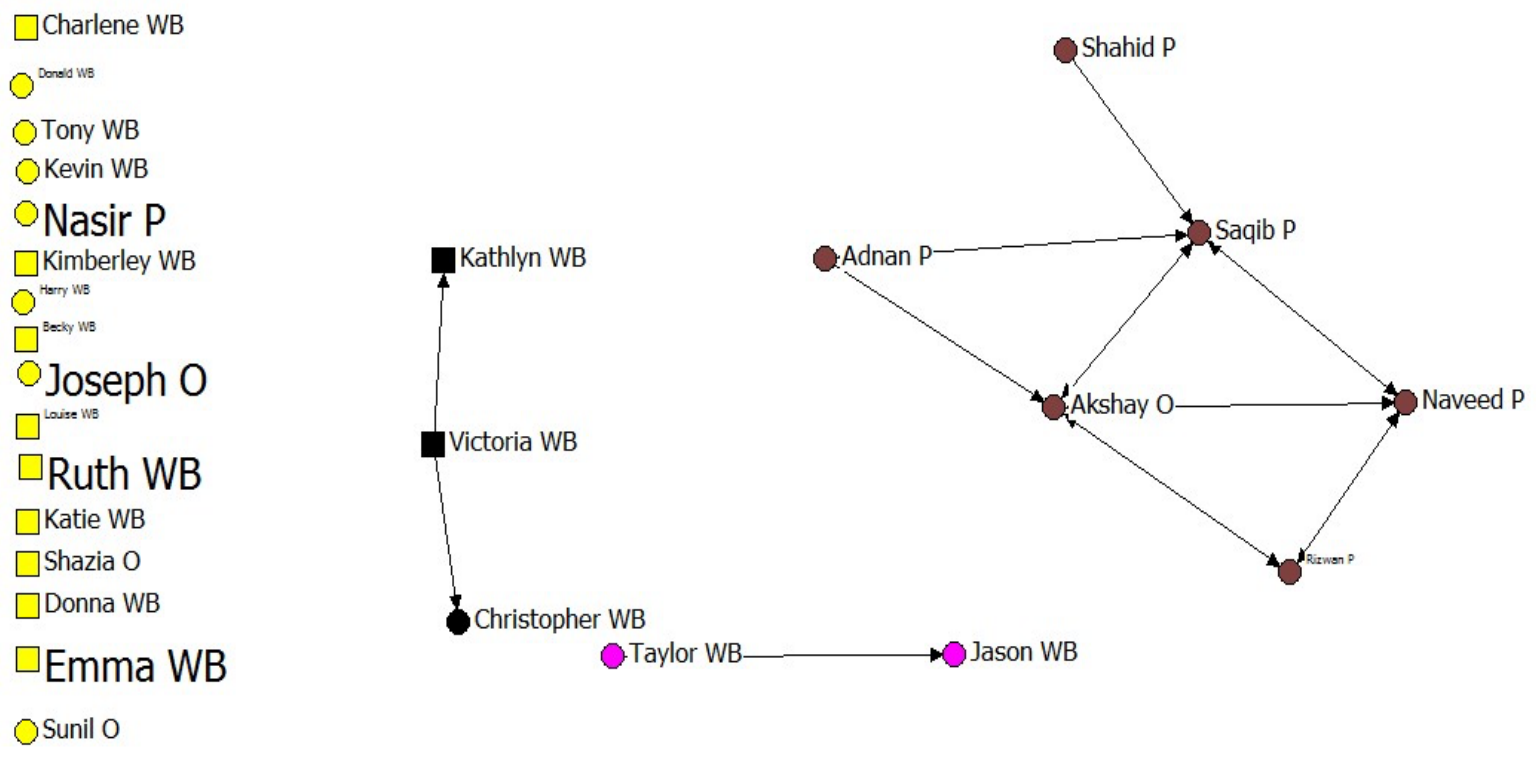

Figure 4 - Mathematics help given/received by friends - predicted case

Therefore, in contrast to the advantaged case, our analysis here reveals a different network and sub-network structure. Ethnicity and gender mediates friendships and access to helping subnetworks in much the same way for both cases, but (i) the network as a whole is more helpful across the classroom in the second, older classroom; and (ii) the cultural capital available to each sub-network and to the Pakistani friendship groups is particularly different. Though friendship sub-networks exist in the predicted case (as in the case of the group of Pakistani boys), these do not confer any special value (access mathematics cultural capital) in relation to the educational field. Members of the sub-networks do offer mutual help, but one that does not hold much store of potential cultural capital relevant in this educational field, and hence, does not have much of the right sort of social capital that is valued in the educational field. As such, we could argue that this classroom seems to have a more equitable peer helping structure, with far more helping going on across subgroups, and friendship having more marginal capital value than in the first case. On the other hand in the first classroom (case 1), peer structure seems to give special advantage to one studious group. However, we do not know how this came about, and whether the differences are due to teaching practices - such as sitting friendship groups together. Alternative explanations due to the maturity of the class (aged 14 against age 12) may be equally relevant. What we do know is that the SNA has in each case objectified the peer social structure and supported our subjective interpretations of events we observed in the classroom.

\section{Discussion and Conclusion}

In this paper, we look at how inequality in education manifests and even reproduces itself through social relations, specifically, social networks within two distinct mathematics classroom cases. Our findings suggest that the structures of social networks are important to how educational capital may be accessed, and this is one way in which the social space operates as a system for reproducing capital in the wider educational field. The result of friendship networks of the kind identified is a particular differentiation of access to educational capital. We also contribute to the existing debate of how ethnicity and gender (and social class as well) affect learning outcomes: we argue that peer-peer relations and networks, and the social capital they offer, are an important mediator.

The literature in the area of social relations and education (or learning that takes place within classrooms) is split between (i) a functional and benign understanding of social capital (based on Coleman's and Putnam's conceptualisation of social capital); and (ii) the critical 
conceptualisation of Bourdieu in which capital offers a power structure used in social domination. We chose to analyse peer group relations from a Bourdieusian perspective, as we felt it necessary to map out the power structure of the classroom in terms of students' hierarchical positioning according to more or less mathematics cultural capital that they possess. We argue that by analysing mutually recognised objective social peer group relations within classrooms, we have revealed 'unequal distribution of the capital valued within a given field' (Ladwig 2013, 378), i.e. unequal distribution of mathematics cultural capital in the educational field that ultimately leads to dominant groups gaining access to further education at the expense of those who drop out of education. If one adopts Coleman's point of view, the well-resourced networks would be understood as being beneficial to those students who belong to them, and the moral imperative would be to try to build such networks for all, enhancing their value to civil society as a whole (see also Putnam [2000]; Adler \&Kwon [2002]; Cordini [2010]). We think there is some merit in both these apparently contradictory perspectives: on the one hand peer networks do seem offer learners access to opportunities and we would want all learners to have rich (in group bonding and cross group bridging) networks. On the other hand in practice boundaries that form around these networks also serve to cut off access to them for some and thus may serve to exclude - even if sometimes it seems to be self-exclusion - and hence exert a symbolic violence on the excluded. In the two classrooms we selected, one guesses that the difference in seating arrangement (or possibly other effects due to pedagogy, policy, or even maturity of the classes) has influenced the differences in peer relations and thus help-giving: the formation of a rather sharply separated studious and other group in one classroom perhaps leading to greater differentiation than within the other classroom where bridging relationships across subgroups seems ot offer more equitable and supporting learning opportunities.

Hence, in this paper we have considered social relations within classrooms and their implications for learning from a social capital point of view. In particular we draw on Lee's (2010) criticism of Bourdieu's imprecision. Thus, we concur that social relations and accessible networks are better understood as not social capital in themselves but potential 'sources of social capital' (Lee 2010, 781). These may or may not lead to, for example, further learning opportunities in classrooms in practice. Additionally, our findings support Von Otter and Stenberg (2015) who argue that in Bourdieu's notion of social capital 'benefits of network relations are determined by characteristics of the network structure: relationships in an advantaged network tend to have higher utility than relationships in a disadvantaged network (p. 999). The classroom peer networks are themselves apparently influenced by ethnicity and gender (probably among other variables such as class that we have not measured). Thus the way peer groups form in the classrooms reflects and constructs the social structure, and mediates access to social capital. This suggests complexity that makes the structure difficult to predict, almost each case looks like an accident where apparently minor differences in conditions (e.g. the school's practice of seating attainment groups together) might emerge downstream as major effects.

We therefore agree that "enhanced educational outcomes is simply not one of bringing more "productive pedagogies" into the classroom if the intercultural relationship that is produced between teachers and students is not also considered' (McFadden \& Munns 2002, 363). One implication for practice and policy is, thus, to attend to the social networks that are facilitated in classrooms, and possibly enrich these via cross-classroom peer and close peer support through 'increased attention to peers and an extended understanding of peer social capital' (Jørgensen 2016,10 ). For example, ability grouping in terms of seating policies within classrooms (with similar attainment levels) may encourage classroom polarisation (see e.g. Ball [2003]) and disaffection within networks with less mathematics cultural capital and lesser social capital (Zevenbergen 2005). We add to this by concluding with the argument that learners can potentially gain access to mathematics cultural capital though social networks that provide more or less mathematics help that might sustain (or curtail) their mathematics learning. It is suggested that friendship sub-networks are one conduit of this help, and because ethnicity and gender mediate friendship, they can also mediate access to mathematics. 
We then also claim to have constructed an appropriate methodology for investigating peer relationships in the classroom that can allow access to social, educational capital. We claim to have done so by constructing a social network analysis tool to delineate networks of variable boundary strength, combining measures (a) help given/received to student by each other and (b) friendship ties inside and outside of the classroom. By only including mutually recognised ties in the analysis (through multiplex analysis), we claim to have constructed a process of objectivisation of students' subjectivities into social networks. By doing so, we have revealed a hidden and unspoken rule of this social space: some learners give and get more help from their peer network than others. We argue that this methodology can an should be made available to future studies of classrooms investigating peer networks and their mediating effects, and the influences of other factors on classroom learning opportunities. We also, however, acknowledge limitations to our substantive claims as, for example, the issue of isolates is not explored further, and especially our analysis misses social class (a crucial element in Bourdieu's theory).

Nevertheless, we align with Bourdieu: that objectivisation of the subjective (and vice versa) is not only desirable but necessary if we are to synthesise the subjective expressions of the students and the researchers' within the social structure of power in the class, thereby unmasking the unspoken rule of what is being held valuable in the educational field (e.g. what is the right kind of social capital that can give access to further educational cultural capital). This is especially so for marginalised students where it is important to create possibilities of opportunities to transform the educational field (see, e.g., Mills [2008]). Therefore our final concluding argument is for the importance of the objective-subjective dialectic in such educational research contexts as a way forward. 


\section{References}

Adler, P.S. \& S.W. Kwon. 2002. "Social Capital: Prospects for a New Concept." The Academy of Management Review 27(1): 17-40. doi: 10.5465/AMR.2002.5922314.

Berndt, T.J. \& K. Keefe. 1996. "Friends' influence on school adjustment: A motivational analysis." In Social motivation: understanding children's school adjustment, edited by J. Juvonen \& K. R. Wentzel, 195-203. New York: Cambridge University Press.

Boaler, J. 1997. "Reclaiming school mathematics: The girls fight back." Gender and Education 9 (3): 285-306. doi: 10.1080/09540259721268.

Bourdieu, P. 1983. "Forms of capital." In Handbook of Theory and Research for the Sociology of Education, edited by J. C. Richards. New York: Greenwood Press.

Bourdieu, P. \& J.C. Passeron. 1977. Reproduction in Education, Society and Culture. London: Sage.

Cairnes, R., H. Xie, \& M.C. Leung. 1998. "The popularity of friendship and the neglect of social networks: toward a new balance." New Directions for Child Development 1998(81): 25-53. doi: 10.1002/cd.23219988104.

Cairns, R. B., J.E. Perrin, \& B.D. Cairns. 1985. "Social structure and social cognition in early adolescence: Affiliative patterns." Journal of Early Adolescence 5(3): 339-355. doi: $10.1177 / 0272431685053007$.

Choudry, S. (2016). Mathematics capital in the classroom and wider educational field: intersections of ethnicity, gender, and social class. PhD Thesis, Manchester: University of Manchester.

Coleman, J.C. 1988. "Social capital in the creation of human capital." American Journal of Sociology 94(supplement): 95-120. doi: 10.1086/228943.

Coradini, O.L. 2010. "The divergences between Bourdieu's and Coleman's notions of social capital and their epistemological limits." Social Science Information 49(4): 563-583. doi: $10.1177 / 0539018410377130$.

DeJordy, R. \& D. Halgin. 2008. An introduction to social network analysis and UCINET. Kingston, Ontario: Queen's School of Business.

Dika, S.L. \& K. Singh. 2002. "Applications of Social Capital in Educational Research: A Critical Synthesis." Review of Educational Research 72(1): 31-60. doi: 10.3102/00346543072001031.

Epstein, J.L. 1983. "The influence of friends on achievement and affective outcomes." In Friends in school, edited by J. L. Epstein \& N. Karweit, 177-200. New York: Academic Press.

Hallinan, M.T. 1983. "Commentary: New directions for research on peer influence." In Friends in school, edited by J. L. Epstein \& N. Karweit, 219-231. New York: Academic Press. 
Hanneman, R.A. \& M. Riddle. 2005. Introduction to social network methods. Riverside, CA: University of California, Riverside.

Heath, S., A. Fuller, \& B. Johnston. 2010. "Young people, social capital and network- based educational decision-making." British Journal of Sociology of Education 31(4): 395-411. doi: $10.1080 / 01425692.2010 .484918$

Jørgensen, C.H.R. 2016. “'Peer social capital' and networks of migrants and minority ethnic youth in England and Spain." British Journal of Sociology of Education. Advance online publication. doi: 10.1080/01425692.2015.1131144.

Kindermann, T.A. 1993. "Natural peer groups as contexts for individual development: The case of children's motivation in school." Developmental Psychology 29(6): 970-977. doi: 10.1037/0012-1649.29.6.970.

Krackhardt, D. \& R. Stern. 1988. Informal networks and organizational crises: An experimental simulation. Social Psychology Quarterly 51(2): 123-140. doi: 10.2307/2786835.

Kutnick, P., Blatchford, P. \& Baines, E. 2005. Pupil groupings in primary school classrooms: sites for learning and social pedagogy? British Educational Research Journal, 28(2): 189208.

Kutnick, P.; J. Sebba, P. Blatchford, M. Galton, J. Thorp, H. MacIntyre, \& L. Berdondini, 2005. The effects of pupil grouping: Literature review, Nottingham: DfES Publications. Research Report 68.

Lee, M. 2010. "Researching social capital in education: some conceptual considerations relating to the contribution of network analysis". British Journal of Sociology of Education 31(6), 779-792. doi: 10.1080/01425692.2010.515111.

McFadden, M. \& G. Munns. 2002. "Student Engagement and the Social Relations of Pedagogy." British Journal of Sociology of Education 23(3): 357-366. doi: 10.1080/0142569022000015409.

Mills, C. 2008. "Reproduction and transformation of inequalities in schooling: the transformative potential of the theoretical constructs of Bourdieu." British Journal of Sociology of Education, 29(1): 79-89. doi: 10.1080/01425690701737481.

Putnam, R. 2000. Bowling alone: The collapse and revival of American community. New York: Simon and Schuster.

Rossem, R.V, M. Vermande, B. Völker, \& C. Baerveldt. 2013. "Social capital in the classroom: a study of in-class social capital and school adjustment." British Journal of Sociology of Education, 36(5): 669-688. doi: 10.1080/01425692.2013.848779.

Scott, J. 2000. Social Network Analysis: A Handbook. London: Sage Publications.

Von Otter, C. \& S.A. Stenberg. 2015. "Social capital, human capital and parent-child relation quality: interacting for children's educational achievement?" British Journal of Sociology of Education 36(7): 996-1016. doi: 10.1080/01425692.2014.883275. 
Wallace, W. L. 1966. Student Culture. Chicago: Aldine.

Wentzel, K. L. \& K. Caldwell. 1997. "Friendships, peer acceptance, and group membership: Relations to academic achievement in middle school." Child development 68(6): 1198-1209. doi: 0.1111/j.1467-8624.1997.tb01994.x.

Zevenbergen, R. 2005. "The construction of a mathematical habitus: implications of ability grouping in the middle years." Journal of Curriculum Studies 37(5): 607-619. doi: $10.1080 / 00220270500038495$. 